\title{
Nasal application of the cationic liposome DC-Chol:DOPE does not alter ion transport, lung function or bacterial growth
}

\author{
P.G. Middleton*, N.J. Caplen**, X. Gao ${ }^{+}$, L. Huang ${ }^{\dagger}$, H. Gaya \\ D.M. Geddes*, E.W.F.W. Alton*
}

Nasal application of the cationic liposome DC-Chol:DOPE does not alter ion transport, lung function or bacterial growth. P.G. Middleton, N.J. Caplen, X. Gao, L. Huang, H. Gaya, D.M. Geddes, E.W.F.W. Alton. CERS Journals Ltd 1994.

ABSTRACT: Liposome-mediated gene transfer is commonly used for in vitro transfection of deoxyribonucleic acid (DNA) into mammalian cells. We and others have recently demonstrated that this can be an effective method for in vivo delivery of plasmid DNA containing the human cystic fibrosis transmembrane conductance regulator (CFTR) gene to mouse models of cystic fibrosis (CF). This suggests that cationic liposomes may be useful for transferring CFTR complementary DNA (cDNA) into the airways of CF subjects. In this study, measurement of nasal potential difference (PD) was used to monitor the efficacy of correction of the CF bioelectric defect and to provide a sensitive assay of epithelial integrity.

We therefore assessed whether the cationic liposome DC-Chol:DOPE altered nasal ion transport parameters, in six normal and three CF subjects. Lung function was also measured as a further marker of safety. Finally, as CF airways are chronically infected, we studied whether DC-Chol:DOPE or DC-Chol:DOPE-DNA complexes altered the bacterial growth and sensitivities of CF sputum.

No significant effect was seen on any of these parameters, suggesting that DCChol:DOPE may be appropriate for use in human trials of liposome-mediated gene therapy for CF.

Eur Respir J., 1994, 7, 442-445.

Despite considerable advances in therapy over the past 20 yrs, most patients with cystic fibrosis (CF) still die from respiratory failure. Following the identification of the bioelectric defect characteristic of $\mathrm{CF}$ [1] and isolation of the $\mathrm{CF}$ gene [2], strategies for gene therapy have been suggested that may arrest the progressive lung damage typical of the disease.

Cationic liposomes are commonly used for gene transfer in vitro, forming stable complexes with the negatively charged deoxyribonucleic acid (DNA) more efficiently than neutral liposomes, and having a potential advantage over viral methods in vivo, since the latter may induce an immune response. Recently, we [3], and others [4], have demonstrated that cationic liposome-mediated cystic fibrosis transmembrane conductance regulator (CFTR) complementary DNA (cDNA) transfection of the airways of $\mathrm{CF}$ mouse models in vivo can correct the bioelectric defect characteristic of $\mathrm{CF}$, suggesting that human gene therapy using these methods is feasible. Although a recent report has demonstrated some cytotoxic effects of cationic liposomes on isolated cells in vitro [5], no adverse reactions were found in our CF mice, either histologically or physiologically.

The principal means of determining the efficacy of gene therapy in human subjects will be the measurement
*Ion Transport Laboratory, National Heart and Lung Institute, London, UK. **Dept of Biochemistry and Molecular Genetics, St Mary's Hospital Medical School, London, UK. 'Laboratory of Drug Targeting, Dept of Pharmacology, University of Pittsburgh School of Medicine, Pittsburgh, PA, USA, ‡ept of Microbiology, Royal Brompton National Heart and Lung Hospital, London, UK.

Correspondence: P.G. Middleton, Ion Transport Laboratory, National Heart and Lung Institute, Manresa Rd, London SW3 6LR, UK

Keywords: DC-Chol:DOPE, gene therapy, liposomes, nose

Received: September 161993

Accepted after revision November 201993

PGM is supported by a Cystic Fibrosis Research Trust Fellowship, EWFWA by a British Heart Foundation Intermediate Fellowship, and the study by the Cystic Fibrosis Research Trust and the British Medical Association HC Roscoe Fellowship.

of airway ion transport. The major abnormalities in $\mathrm{CF}$ include a raised (more negative) baseline potential difference (PD), increased sodium absorption and decreased chloride secretion. The baseline PD depends on a combination of active ion transport processes and the total epithelial resistance, which relates mainly to the integrity of the tight junctions. Thus, a decrease in the baseline $\mathrm{PD}$ of the $\mathrm{CF}$ airway epithelium following gene therapy could occur either as a result of damage, or through correction of the bioelectric defect. The increased sodium absorption in $\mathrm{CF}$ is commonly studied using the sodium channel blocker amiloride, and the decreased chloride secretion by the application of isoprenaline, which induces chloride secretion through cyclic AMP mediated pathways. Changes in the charge of a lipid membrane can alter ion channel open probability [6], so it is possible that the positively charged liposome could alter the characteristics of sodium or chloride channels. Thus, administration of cationic liposomes alone could theoretically alter both the baseline nasal PD and the response to various interventions. Another theoretical effect of cationic liposomes in CF airways in vivo would be their incorporation into the cell wall of the bacterial flora, altering their susceptibility to antibiotics that induce bacterial cell wall lysis. 
We have, therefore, studied whether the cationic liposome DC-Chol:DOPE altered the bioelectric properties of a human respiratory epithelium in vivo with two aims: firstly, to confirm safety; and, secondly, to ensure that they do not affect the bioelectric properties which will be used in vivo to monitor gene expression. As an additional measure of safety, lung function was also performed prior to and following nasal inhalation of the liposome. Finally, in view of the chronic infection typically found in the airways of the CF subjects, we also studied the effect of liposomes and liposome-DNA complexes on the common pathogens found in the sputum of $\mathrm{CF}$ subjects.

\section{Materials and methods}

\section{Liposome}

Liposomes were prepared from DC-Chol and DOPE (3:2 molar ratio) by sonication as described previously [7], and were stored for less than 28 days at $4^{\circ} \mathrm{C}$. DCChol:DOPE was diluted in sterile water and delivered to each nostril using a pump spray (mass median aerosol diameter of $\sim 60 \mu \mathrm{m})$ in 10 equal doses $\left(50 \mu \mathrm{g} \cdot 200 \mu \mathrm{l}^{-1}\right)$, administered every $15 \mathrm{~min}$ for a total of $135 \mathrm{~min}$. This period was chosen to match that for our proposed gene therapy trial, with the aim of continuously bathing the nasal epithelium in liposome-DNA complexes for at least $2 \mathrm{~h}$. As the time to transport exogenous substances along the floor of the nose of CF subjects is of the order of 15-30 $\mathrm{min}$ [8], we chose repeated doses every $15 \mathrm{~min}$ to maximize the contact time.

\section{Subjects}

Six nonsmoking males, mean age 27 yrs, (range 21-36 yrs), with no history of any respiratory disorders, taking no regular medications, were studied as normal subjects. Three nonsmoking males with CF, aged 19-23 yrs, homozygous for the $\Delta \mathrm{F} 508$ mutation were also studied - all had abnormal sweat tests, and were pancreasinsufficient. No subject had suffered an upper respiratory tract infection for at least one month prior to study. The study was approved by the Hospital Ethics Committee and all subjects gave informed consent.

\section{Physiology}

Nasal PD was measured along the floor of each nostril, using the method described previously [8], with a minor modification to allow perfusion of the surface epithelium. The maximal PD for each nostril was measured, and the catheter positioned at this point for subsequent perfusion. Following measurement of the baseline $\mathrm{PD}$, the effect of sequential superfusion with the following solutions was measured: amiloride $\mathrm{HCl}(100 \mu \mathrm{M})$, amiloride in a low chloride $(6 \mathrm{mM})$ solution (gluconate substitution), and finally amiloride $\mathrm{HCl}$ in low chloride solution with isoprenaline $(10 \mu \mathrm{M}$ as the hemisulphate salt). The results from both nostrils were averaged for each patient at each time-point.

These measurements were performed prior to, and at one and five days following nasal application of the DCChol:DOPE. Nasal PD was not measured immediately following the liposome inhalation, as perfusion may accelerate removal of the liposome from the nose, and also to maintain uniformity with our proposed gene therapy trial. Measurements of spirometry (Vitalograph Compact) were taken before, immediately after, and 1 and 5 days after liposome application.

\section{Bacteriology}

Samples of sputum from $10 \mathrm{CF}$ patients were individually homogenized with an equal volume of Ringer's saline solution, and three $1 \mathrm{ml}$ aliquots were then taken. DC-Chol:DOPE $(250 \mu \mathrm{g})$ was added to the first aliquot, DC-Chol:DOPE $(250 \mu \mathrm{g})$ complexed with DNA (50 $\mu \mathrm{g}$ pCMV $\beta$ Clontech Inc.) to the second aliquot, and an equal volume of normal saline added to the control. Samples were then cultured in parallel on chocolate agar, McConkey's agar, mannitol salt agar, Difco Pseudomonas sp. medium, MAST Pseudomonas cepacia medium, and Sabouraud medium, and incubated at $37^{\circ} \mathrm{C}$. After 2 days, the cultures were quantitated, and sensitivities assessed [9]. The Wilcoxon signed rank test was used for statistical analysis, and the null hypothesis rejected at $\mathrm{p}<0.05$.

\section{Results}

\section{Physiology}

Nasal inhalation of the liposome was well-tolerated by all subjects. Nasal PDs prior to and following liposome are shown in figure 1. There was no statistically significant difference between any of the measurements on the three different days for either group. Spirometry results are shown in table 1. Again, no significant changes were seen following liposome inhalation.

\section{Bacteriology}

Positive sputum cultures in the $10 \mathrm{CF}$ patients included Pseudomonas aeruginosa (8), Staphylococcus aureus (4), and Pseudomonas cepacia (1). There was no significant change in the colony counts following the addition of either liposome or DNA-liposome complexes. One culture of mucoid Pseudomonas Aeruginosa showed a small change in antibiotic sensitivity following the addition of DNA-liposome, with resistance to 12 of 16 antibiotics, compared to 10 of 16 antibiotics in the liposome and control groups. All other samples showed identical antibiotic sensitivities. 
Table 1. - Lung function results prior to and following liposome inhalation for normal and CF subjects

\begin{tabular}{|c|c|c|c|c|c|c|c|c|c|}
\hline \multirow{4}{*}{$\begin{array}{l}\text { Normal } \\
(n=6)\end{array}$} & \multirow{4}{*}{$\begin{array}{l}\mathrm{FEV}_{1} l \\
\mathrm{FVC} l\end{array}$} & \multirow{2}{*}{\multicolumn{2}{|c|}{$\begin{array}{c}\text { Before } \\
\text { liposome }\end{array}$}} & \multicolumn{6}{|c|}{ After liposome } \\
\hline & & & & \multicolumn{2}{|c|}{ Immediately } & \multicolumn{2}{|c|}{1 day } & \multicolumn{2}{|c|}{5 days } \\
\hline & & 4.08 & $(0.24)$ & 4.09 & $(0.24)$ & 3.98 & $(0.25)$ & 3.97 & $(0.24)$ \\
\hline & & 5.26 & $(0.19)$ & 4.95 & $(0.27)$ & 4.81 & $(0.28)$ & 5.08 & $(0.16)$ \\
\hline $\mathrm{CF}$ & $\mathrm{FEV}_{1} l$ & 1.21 & $(0.30)$ & 1.21 & $(0.36)$ & 1.18 & $(0.29)$ & 1.09 & $(0.21)$ \\
\hline$(\mathrm{n}=3)$ & $\mathrm{FVC} l$ & 2.71 & $(0.51)$ & 2.80 & $(0.54)$ & 2.57 & $(0.44)$ & 2.65 & $(0.39)$ \\
\hline
\end{tabular}

Data are presented as mean, and SEM in parenthesis. CF: cystic fibrosis; $\mathrm{FEV}_{1}$ : forced expiratory volume in one second; FVC: forced vital capacity.

\section{a) Cystic fibrosis}

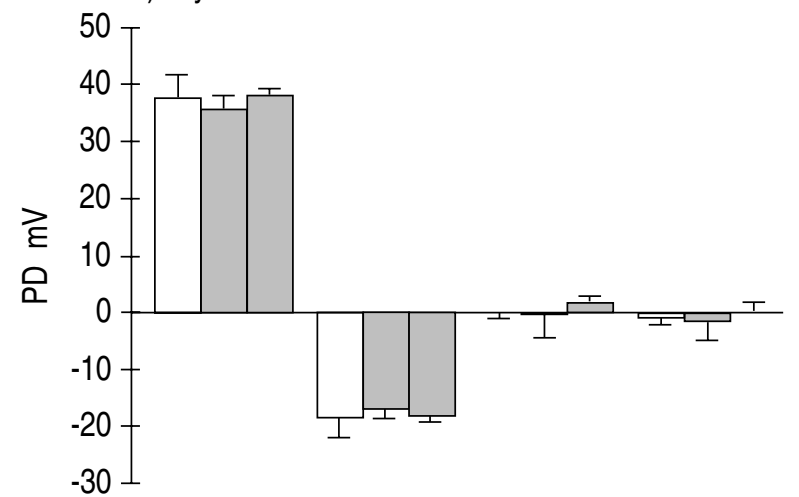

b) Normal

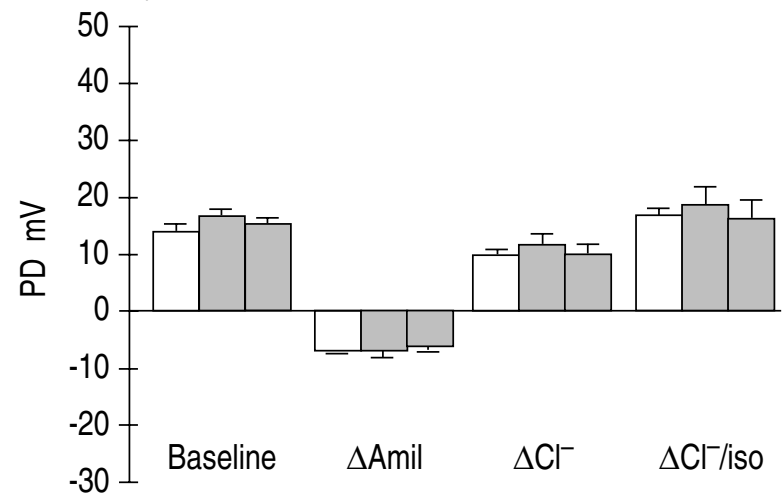

Fig. 1. - Absolute nasal potential difference (PD) measurements for the three days tested: a) Cystic fibrosis (CF) subjects $(n=3) ; \quad b)$ normal subjects $(n=6)$. Baseline; $\Delta$ Amil: change following amiloride $(100 \mu \mathrm{m}) ; \Delta \mathrm{Cl}:$ change due to low chloride $(6 \mathrm{mM})$ solution; $\Delta \mathrm{Cl}$-/iso: change due to both isoprenaline $(10 \mu \mathrm{M})$ and low chloride $(6 \mathrm{mM})$ solutions. Error bars indicate sEM. $\square$ : Day 0 pre-liposome; $\square$ : Day 1 post-liposome; $\square$ : Day 5 post-liposome.

\section{Discussion}

We have recently demonstrated that in vivo CFTR cDNA transfection with DC-Chol:DOPE can correct the characteristic ion transport defect in the airways of the mouse model of $\mathrm{CF}$ created by insertional mutagenesis [3]. No deleterious effect of cationic liposomes on airway ion transport or histology was seen. Although DCChol:DOPE has been approved for use in human trials of gene therapy for advanced malignancy [10], prior to its use in the airways of human subjects with $\mathrm{CF}$, we sought confirmatory evidence that DC-Chol:DOPE is safe, and does not affect the ion transport properties of the human respiratory epithelium.

Nasal PD is a sensitive indicator of epithelial integrity, and can be used to measure subtle changes of epithelial damage [11]. Thus, the constant baseline nasal PD throughout the study suggests that no significant damage occurred. This, together with the stable lung function and the lack of effect on sputum bacteriology, provides preliminary evidence for the safety of a single dose of this cationic liposome in the human respiratory tract, at least over the five day period studied. As we did not measure the nasal bioelectrics until $24 \mathrm{~h}$ following inhalation, we may have missed a transient effect resolving completely by this time. Further safety studies will be required before DC-Chol:DOPE is administered to the lower airways, or given repeatedly. To the best of our knowledge, no studies of the effect of cationic liposomes on the human respiratory epithelium in vivo have been reported. Our findings are in accord with a previous study showing that phosphatidylcholine, a neutral liposome, has no acute deleterious effect on lung function as measured by spirometry in 10 human subjects [12].

The nasal epithelium also demonstrates the characteristic chloride impermeability found in CF [11], and will be used to measure the degree of correction obtained in trials of gene therapy for CF. The stable responses to amiloride, low chloride and isoprenaline solutions throughout the study suggest that DC-Chol:DOPE does not directly change the nasal ion transport properties measured.

In conclusion, the lack of effect of the cationic liposome DC-Chol:DOPE on any of the parameters studied suggests that this liposome is appropriate for our proposed trials of gene therapy for $\mathrm{CF}$.

Acknowledgements: The authors would like to thank R. Williamson, M. Chadwick, P. Webber, B. Hughes, S. Doyle, together with the subjects who took part in this study.

\section{References}

1. Quinton PM. Chloride impermeability in cystic fibrosis. Nature 1983; 301: 421-422.

2. Riordan JR, Rommens JM, Kerem B, et al. Identification of the cystic fibrosis gene: cloning and characterization of complementary DNA. Science 1989; 245: 1066-1073.

3. Alton EWFW, Middleton PG, Caplen NJ, et al. Noninvasive 
liposome-mediated gene delivery can correct the ion transport defect in cystic fibrosis mutant mice. Nature Gen 1993; 5: 135-142.

4. Hyde SC, Gill DR, Higgins CF, et al. Correction of the ion transport defect in cystic fibrosis transgenic mice by gene therapy. Nature 1993; 362: 250-255.

5. Robinson CB, Malone RW, Jessee J, Gebeyehu G, Wu R. Successful gene transfection of respiratory epithelium in vitro using polyamine containing cationic lipids. Am Rev Respir Dis 1993; 147 (4): A546.

6. Bell J. The Sarcoplasmic Reticulum Potassium Channel. Lipid Effects. In: Miller C, ed. Ion Channel Reconstitution. London, Plenum Press, 1986; pp. 469-482.

7. Gao XA, Huang L. A novel cationic liposome reagent for efficient transfection of mammalian cells. Biochem Biophys Res Commun 1991; 179: 280-285.
8. Middleton PG, Geddes DM, Alton EWFW. Effect of amiloride and saline on nasal mucociliary clearance and potential difference in cystic fibrosis and normal subjects. Thorax 1993; 48: 812-816.

9. Stokes EJ, Waterworth PM. Association of Clinical Pathologists, Broadsheet No. 55 (Revised). 1972;

10. Nabel GJ, Chang A, Nabel EG, et al. Immunotherapy of malignancy by in vivo gene transfer into tumors. Human Gene Therapy 1992; 3: 399-410.

11. Knowles M, Gatzy J, Boucher R. Increased bioelectric potential difference across respiratory epithelia in cystic fibrosis. N Engl J Med 1981; 305: 1489-1495.

12. Thomas DA, Myers MA, Wichert B, Schreier H, GonzalezRothi RJ. Acute effects of liposome aerosol inhalation on pulmonary function in healthy human volunteers. Chest 1991; 99: 1268-1270. 